\title{
A STUDY TO ASSESS THE EFFECTIVENESS OF HELFER SKIN TAP TECHNIQUE ON PAIN ASSOCIATED WITH INTRAMUSCULAR INJECTION AMONG ADULT PATIENTS IN SELECTED HOSPITALS OF NAVI MUMBAI
}

\author{
Tanoj Patidar \\ Second year M.S.c Nursing, \\ D Y Patil School of Nursing, Nerul, Navi Mumbai
}

\begin{abstract}
-
Background: Pain management is an integral part of nursing and Nurses have a responsibility to effectively manage patient's pain. Nurses and doctors play a greater role in minimizing the pain and discomfort during any invasive procedure. Helfer skin tap technique offers a painless IM injection experience. In this technique rhythmic tapping before and during injection over the skin at the site of injection keeps the muscle relaxed and stimulates large diameter fibers.

Aims and Objective: To assess the effectiveness of Helfer skin tap technique on pain associated with intramuscular injection among adult patients. To identify the association between the demographic variables and post procedure score on pain associated with intramuscular injection among adult patients. Methods: A quantitative research approach and crossover design was adopted; 40 patients were selected using non probability purposive sampling in selected hospitals of Navi Mumbai. Data was collected using a questionnaire and selfreporting numerical pain rating scale.
\end{abstract}

Results: Study results show that Majority of the respondent belonged to the age group 31-45 years with a frequency of 17 (42.5\%). Representation of male respondent was 23(57.5\%) and rest of the respondent belonged to female gender. They were educated up to primary level with elementary occupation; their monthly income ranged from Rs. 19,516 - 29,199 and belonged to upper lower class. The maximum respondent was found married 37(92.5\%) and had a BMI ranging from 18.524.9(Normal weight). All the respondent was exposed to IM injection during their stay in the hospital. At Post-intervention assessment using the routine technique, $3(7.5 \%)$ respondent reported mild pain and $37(92.5 \%)$ reported moderate pain. At Post-intervention assessment using Helfer technique 14(35\%) respondents reported mild pain and $26(65 \%)$ reported moderate pain. A non-parametric McNemar test was conducted to test the post-test pain comparison between routine technique and Helfer skin tap technique. The significance level is 0.003 , which indicates that there exists a statistically significant difference in pain between routine technique and Helfer skin tap technique. There was no significant association between the Helfer skin tap technique and the selected demographic variables at $0.05 \%$ level of significance. Weight and BMI shows little significance $0.016 \& 0.043$ respectively. The study findings revealed that, Helfer skin tap technique is effective in reducing intramuscular injection pain in adult patient.

KEYWORDS: Assess Effectiveness, Intramuscular Injection, Helfer skin tap technique, Routine technique

\section{INTRODUCTION}

Pain is a multidimensional phenomenon, it is unique and difficult to define, it is an individual and subjective experience, and no two individuals experience of the pain is the very same. Injection pain is associated with the penetration of the skin by the needle and to the mechanical and chemical effects of the drug during and after its injection into muscles. Effective pain management not only reduces physical discomfort, but also improves quality of life. Helfer skin tap technique is non pharmacological technique of IM injection and are not difficult to administer and complicated. Few benefits are:

- Relaxing the skin

- diminish pain

- It provides superficial vasodilatation,

- Giving anesthetic effect (gate theory)

The Aim of this study is to help the nurses to reduce procedural pain during intramuscular injections. Hence this study is taken up to assess the effectiveness of Helfer skin tap technique to reduce the pain during intramuscular injections in adults. 


\section{International Journal of Engineering Applied Sciences and Technology, 2021 \\ Vol. 5, Issue 9, ISSN No. 2455-2143, Pages 137-140 \\ Published Online January 2021 in IJEAST (http://www.ijeast.com)}

\section{NEED OF THE STUDY}

Injections are the most frequent painful procedure during hospitalization. A fundamental principle of responsible medical care is ' do not harm' since pain is harmful to everyone, the healthcare workers are committed in preventing harm to their patients. A study conducted to compare the effect of Helfer Skin Tap Technique V/s Routine Technique on the pain perception among adult patients receiving intramuscular injection. A Quasi-experimental study using cross over, post-test only design was conducted at Civil Hospital, Gurgaon, Haryana. Total 60 subjects were conveniently selected to Group I and Group II. Numerical pain rating scale was used to assess the level of pain. Findings revealed that there was a significant difference in mean pain scores of the patients while receiving intramuscular injection with Helfer Skin Tap Technique (mean $\pm \mathrm{SD}=1.13 \pm 0.94)$, compared to that with Routine Technique $($ mean $\pm \mathrm{SD}=5.63 \pm 1.20)(\mathrm{p}<0.001)$. There was a significant association of mean post-test pain scores of patients with occupation and marital status $(\mathrm{p} \leq 0.01)$ but not with gender and educational background and occupation.

A study conducted to assess the effect of Helfer Rhythmic skin tap technique on procedural pain among 82 patients receiving IM injection at Govt. Medical college, Kerala. Pain rating scale was used to collect data and purposive sampling technique was used. This study shows that the use of HST is highly effective in reducing the pain during IM injection. A very few studies were conducted on this aspect. Especially of many Indian studies have not been carried out on this aspect. Thus the review of literature related to prevalence of pain associated with intramuscular injection and Helfer skin tap technique says that there is considerable need of this type of study to reduce to procedural pain related to intramuscular injections. Since Helfer skin tap technique has proved to bring about a great deal of change in the level of pain associated with intramuscular injection.

\section{STATEMENT OF THE PROBLEM}

A study to assess the effectiveness of Helfer skin tap technique on pain associated with intramuscular injection among adult patients in selected hospitals of Navi Mumbai.

\section{OBJECTIVE}

To assess the effectiveness of Helfer skin tap technique on pain associated with intramuscular injection among adult patients.

To identify the association between the demographic variables and post procedure score on pain associated with intramuscular injection among adult patients.

\section{HYPOTHISIS}

- Ho(1): There will be no significant effect of Helfer skin tap technique and pain reduction associated with intramuscular injection.

- $\quad \mathbf{H 0}(2)$ : There will be no significant association between Helfer skin tap technique and pain associated with intramuscular injection and with their selected demographic variables.

- H1(1): There will be a significant effect of Helfer skin tap technique and pain reduction associated with intramuscular injection.

- H1(2): There will be a significant association between Helfer skin tap technique and pain associated with intramuscular injection and with their selected demographic variables.

\section{MATERIAL AND METHODS}

A cross over design with a quantitative research approach was adopted for the present study. The study was conducted in the IPD of D Y Patil Hospital, Nerul Navi Mumbai with the sample size of 40 . Non probability Purposive sampling technique was used. In this study samples were adult patients receiving intramuscular injection. Data was collected using a questionnaire and self-reporting numerical pain rating scale.

\section{RESULTS}

The demographic variables were analysed by using descriptive measures. (frequency and percentage) The pain was analysed by using descriptive statistics. The effect of Heifer skin tap technique on pain associated with intramuscular injection and its association with demographic variable was analysed by using non parametric (chi square, McNemar) test.

\section{FINDING RELATED TO DEMOGRAPHIC DATA}

Among 40 patient's majority of the respondent belonged to the age group 31-45 years with a frequency of $17(42.5 \%)$. Representation of male respondent was 23(57.5\%) and rest of the respondent belonged to female gender. They were educated up to primary level with elementary occupation; their monthly income ranged from Rs. 19,516 - 29,199 and belonged to upper lower class. The maximum respondent was found married $37(92.5 \%)$ and had a BMI ranging from 18.5-24.9(Normal weight). All the respondent was exposed to IM injection previously. 


\section{FINDING RELATED TO PRE AND POST PAIN SCORE WITH ROUTINE AND HELFER TAP TECHNIQUE.}

Table 1 Showing pre and post pain score with Routine and Helfer tap technique.

Pre pain score assessment was done only to control confounding variables. Comparison is done for post pain score with Routine and Helfer tap technique.

\begin{tabular}{|l|l|l|l|l|}
\hline \multirow{2}{*}{} & \multicolumn{2}{|l|}{ Routine } & \multicolumn{2}{l|}{ Helfer } \\
\cline { 2 - 5 } & Pre & Post & Pre & Post \\
\hline No pain & 36 & 0 & 37 & 0 \\
\hline Mild pain & 4 & 3 & 3 & 14 \\
\hline Moderate pain & 0 & 37 & 0 & 26 \\
\hline
\end{tabular}

Table 1

1.In the pre assessment of pain in Routine technique $36(90 \%)$ respondents reported No pain and $4(10 \%)$ were reported mild pain. In the Post procedure assessment of routine technique 3 (7.5\%) respondents reported mild pain and 37 (92.5\%) were reported moderate pain.

2. In the pre assessment of pain in Helfer technique 37 (92.5\%) respondents reported No pain and $3(7.5 \%)$ reported mild pain. In the Post procedure assessment of Helfer technique 14 (35\%) respondents reported mild pain and $26(65 \%)$ reported moderate pain.

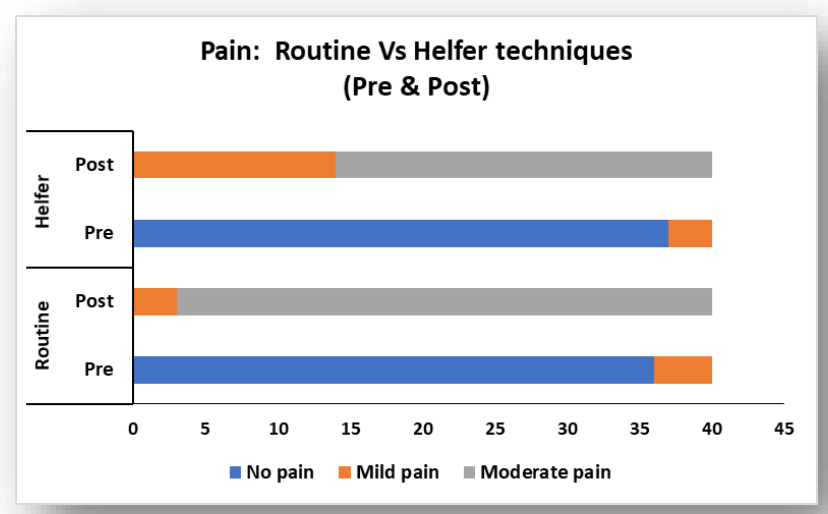

Figure 1

\begin{tabular}{|l|l|}
\hline SR.NO. & $\begin{array}{l}\text { LIST OF COMMON IM DRUGS GIVEN TO } \\
\text { RESPONDENT }\end{array}$ \\
\hline
\end{tabular}

\begin{tabular}{|l|l|}
\hline 1. & Antibiotics \\
2. & Analgesics \\
3. & Antiemetic's \\
4. & Vitamins \\
5. & Iron supplements \\
\hline
\end{tabular}

FINDING RELATED TO EFFECTIVENESS OF HELFER SKIN TAP TECHNIQUE ON PAIN ASSOCIATED WITH INTRAMUSCULAR INJECTION AMONG ADULTS

Table 2 Eeffectiveness of Helfer skin tap technique on pain associated with intramuscular injection among adults.

\begin{tabular}{|l|l|l|l|l|}
\hline \multicolumn{2}{|c|}{} & \multicolumn{2}{|l|}{$\begin{array}{l}\text { Helfer technique post } \\
\text { score }\end{array}$} & \multirow{2}{*}{ Total } \\
\cline { 3 - 5 } \multicolumn{2}{|c|}{} & $\begin{array}{l}\text { Mild } \\
\text { pain }\end{array}$ & $\begin{array}{l}\text { Moderate } \\
\text { pain }\end{array}$ & \\
\hline \multirow{3}{*}{$\begin{array}{l}\text { Routine } \\
\text { technique } \\
\text { Post score }\end{array}$} & \multirow{2}{*}{\begin{tabular}{l} 
Mild pain \\
\cline { 3 - 5 }
\end{tabular}} & 2 & 1 & 3 \\
\cline { 3 - 5 } & Moderate & 12 & 25 & 37 \\
\cline { 3 - 5 } & $32.4 \%$ & $67.6 \%$ & $100.0 \%$ \\
\hline \multirow{2}{*}{ Total } & 14 & 26 & 40 \\
\cline { 3 - 5 } & $35.0 \%$ & $65.0 \%$ & $100.0 \%$ \\
\hline
\end{tabular}

Table 2

\begin{tabular}{|c|c|c|c|c|}
\hline \multicolumn{5}{|c|}{ Hypothesis Test Summary } \\
\hline & Null Hypothesis & Test & Sig. & Decision \\
\hline 1 & $\begin{array}{l}\text { The distributions of different values } \\
\text { across rpost code and hfpost_code } \\
\text { are equally likely. }\end{array}$ & $\begin{array}{l}\text { Related- } \\
\text { Samples } \\
\text { McNemar Test }\end{array}$ & $.003^{1}$ & $\begin{array}{l}\text { Reject the } \\
\text { null } \\
\text { hypothesis }\end{array}$ \\
\hline
\end{tabular}

Figure 2

Effectiveness of Helfer skin tap technique on pain associated with intramuscular injection among adults. A non-parametric McNemar test was conducted to test the post-test pain comparison between routine technique and Helfer skin tap technique as design of study is cross over, which shows that there exists a statistically significant difference in pain between 
routine technique and Helfer skin tap technique. Data needs to be interpreted cautiously in view of small sample size.

\section{FINDING RELATED TO ASSOCIATION BETWEEN THE DEMOGRAPHIC VARIABLES AND POST PROCEDURE SCORE ON PAIN ASSOCIATED WITH INTRAMUSCULAR INJECTION AMONG ADULTS}

There was no significant association between the Helfer skin tap technique and the selected demographic variables at $0.05 \%$ level of significance. Weight and BMI shows little significance and it may be due to lesser sample size and some cells are less than 5. otherwise no other demographic variable and post pain are associated significantly, So the researcher rejects the research hypothesis and accepts the null hypothesis.

\section{CONCLUSION}

To assess the effectiveness of Helfer skin tap technique A nonparametric McNemar test was conducted to test the post-test pain comparison between routine technique and Helfer skin tap technique as design of study is cross over, asymptotic significance is displayed. The significance level is .05 and actual significance is .003 , which shows that there exists a statistically significant difference in pain between routine technique and Helfer skin tap technique. hence $\mathrm{H}_{01}$ rejected and alternative hypothesis $\mathrm{H}_{1}$ is accepted. There was no significant association between the Helfer skin tap technique and the selected demographic variables at $0.05 \%$ level of significance. weight and BMI shows little significance 0.016 \& 0.043 respectively and it may be due to lesser sample size or some cells are less than 5 . otherwise no other demographic variable and post pain are associated significantly, hence $\mathrm{H}_{02}$ accepted and alternative hypothesis $\mathrm{H}_{2}$ is rejected.

\section{REFERENCES}

[1] Zore Gitanjali, Dias Ragina, 2014, Effectiveness of nursing interventions on pain associated with intramuscular injection. IJSR volume 3 Issue 6, ISSN (online) 23197064.

[2] PV Abhija, 2015, A study to evaluate the effectiveness of heifer skin tap technique on pain associated with intra muscular injection among hospitalized adults in selected hospital at Coimbatore (Doctoral dissertation, Annai Meenakshi College of Nursing, Coimbatore).

[3] Jyoti G, Arora S, Sharma B, 2018, Helfer Skin Tap Technique for the IM injection pain among adult patients. Nursing and Midwifery Research. DOI: 10.33698/NRF0236

[4] Shah S., Narayanan A.2016, Effect of Helfer Rhythmic skin tap technique on procedural pain among patients receiving intramuscular injection. Manipal Journal of Nursing and Health Sciences, 2(1),3-9.

[5] Malkin B, 2008, Are technique used for intramuscular injection based on research evidence in nursing times. 2008; 104 (50151): 48-51.

[6] Therese Maria, Devi Suriya. 2014, Effectiveness of Helfer skin tap technique and routine technique on pain reduction among patients receiving intramuscular injection at Government General Hospital, Puducherry. ISSN (online): 2319-7064.

[7] Serena S. 2010, Rhythmic skin tapping: an effective measure to reduce procedural pain during IM injection. Nursing Journal of India, 101(8), 178-180

[8] Cherian AT.,2017 Effectiveness of Rhythmic Skin Tapping on pain during Intra Muscular (IM) injection among male adults in a selected hospital at Mangalore. International Journal of Nursing Education and Research. DOI: $10.5958 / 2454-2660.2017 .00020 .5$

[9] Tomar G, Kalyani V.,2019,Pain and intramuscular injection: helfer skin tap: systematic analysis. DOI:http://dx.doi.org/10.24327/ijrsr.2019.1008.3903

[10] Soliman HM, Hassnein AA.2016, Efficacy of Helfer skin tapping technique on pain intensity as perceived by the patients receiving intramuscular injection. International journal of Nursing Didactics.DOI: 10.15520

[11] Sivapriya S, Kumari LA. 2015, Study to Assess the Effectiveness of Helfer's Skin Tap Technique on Pain during Intramuscular Injection among Neonates Born in Labour Room of a Selected Tertiary Level Hospital. International Journal of Science and Research.volume 4 issue 4, Pages. 547-552

[12] G. Bhuvaneswari,V. Thulasiya, 2018, Assess the effectiveness of Helfer skin tapping techniques on pain during vaccination intramuscular injection among the infants in primary health centre neamam. Research Journal of Pharmacy and Technology. DOI:10.5958/0974-360

[13] Suhrabi Z, Taghinejad H., 2014,Effect of acupressure (UB32) on pain intensity in intramuscular injections. Iranian journal of nursing and midwifery research. 2014Jan;19(1) page no 24-27

[14] Kara D, Yapucu Güneş Ü.,2014, The effect on pain of three different methods of intramuscular injection: A randomized controlled trial. International journal of nursing practice. DOI: 10.1111/ijn. 12358

[15] Suganandam DK, Anand JR, Rajan A, Singh G, Yadav BK. An experimental study to determine the effectiveness of blunt pressure technique on pain response among patients receiving intramuscular injection. Indian Journal of Pain. 2020 Jan 1;34(1):34-38 DOI: 10.4103/ijpn.ijpn_51_19 